\title{
Rectumcancerregisteret gir kvalitetsforbedring i kreftbehandlingen
}

\author{
Arne Wibe ${ }^{1}$, Elisabeth Svensson ${ }^{2}$, Tormod Bjerkeset ${ }^{3}$, Erik Carlsen ${ }^{4}$, \\ Frøydis Langmark ${ }^{2}$, Jarle Norstein ${ }^{2}$, Johan N. Wiig ${ }^{5}$ og Odd Søreide ${ }^{6}$, \\ på vegne av Norsk Rectum Cancer Gruppe \\ ${ }^{I}$ Kirurgisk avdeling, Regionsykehuset $i$ Trondheim \\ ${ }^{2}$ Kreftregisteret \\ ${ }^{3}$ Kirurgisk avdeling, Innherred Sykehus \\ ${ }^{4}$ Kirurgisk avdeling, Ullevål Sykehus \\ ${ }^{5}$ Kirurgisk avdeling, Det Norske Radiumhospital \\ ${ }^{6}$ Sintef Unimed, Senter for Medisinsk Metodevurdering
}

Korrespondanse: Arne Wibe, Kirurgisk avdeling, Regionsykehuset i Trondheim, 7006 Trondheim

Telefon: 73869161 telefax 73867428 E-post arne.wibe@medisin.ntnu.no

\begin{abstract}
SAMMENDRAG
Resultatene etter operasjon for kreft i endetarmen har vært preget av høy frekvens av lokalt residiv og derav lav overlevelse. Resultater blant kurativt opererte i Norge i perioden 1986-88 viste at $28 \%$ utviklet lokalt residiv og bare 55\% overlevde fem år. For å bedre prognosen ved endetarmskreft (rectumcancer) ble det $\mathrm{i}$ 1993 startet et nasjonalt prosjekt, og hensikten med denne studien er å evaluere effekten av de tiltak som ble iverksatt for å heve kvaliteten av behandlingen. Prosjektet har fokusert på å optimalisere kirurgisk behandling ved å innføre operasjonsmetoden "Total Mesorectal Excision" (TME). I tillegg har en lagt vekt på å standardisere de patologisk anatomiske undersøkelsene. En rekke kurs er blitt arrangert for å lære kirurgene den nye operasjonsteknikken, mens patologer har gjennomgått kurs for å sikre kvaliteten i vurderingen av operasjonspreparatene. Et nasjonalt register for endetarmskreft, etablert og drevet av fagmiljøene, ble opprettet ved Kreftregisteret. Fra dette sentrale Rectumcancerregisteret får alle kirurgiske avdelinger regelmessige tilbakemeldinger om sine egne resultater. Fra november 1993 til desember 1999 ble det diagnostisert 5382 nye tilfeller av endetarmskreft i Norge. Blant de 3432 (64\%) som ble kurativt operert var det $8 \%$ som utviklet lokalt residiv etter en median observasjonstid på 31 måneder, og av de under 75 år var den estimerte 5-års overlevelsen 71\%. I 1999 ble mer enn 95\% av pasientene operert med TME teknikken. Det nasjonale samarbeidsprosjektet for kreft i endetarmen har hittil redusert frekvensen av lokale residiver fra $28 \%$ til $8 \%$ og øket 5 -års overlevelsen fra $55 \%$ til $71 \%$. Spesialutdanning av kirurger og patologer, og etablering av Rectumcancerregisteret har vært viktige kvalitetsforbedrende tiltak i norsk kreftbehandling.
\end{abstract}

Wibe A, Svensson E, Bjerkeset T, Carlsen E, Langmark F, Norstein J, Wiig JN, Søreide O, on behalf of Norsk Rectum Cancer Gruppe. The Norwegian Rectal Cancer Registry entails quality improvement in cancer treatment. Nor J Epidemiol 2001; 11 (2): 159-163.

\section{ENGLISH SUMMARY}

The outcome following rectal cancer surgery has been characterised by high local recurrence rates and low survival. In a Norwegian national audit, $28 \%$ of the patients developed local recurrence, and the 5 -year survival was $55 \%$ (patients $<75$ years, treated between 1986 and 1988). Similar results have been reported from other countries. In 1993, the Norwegian surgical community decided to improve the standards of treatment, and a comprehensive educational program was launched. Norwegian surgeons were trained in the Total Mesorectal Excision (TME) technique, a "new" meticulous rectal dissection technique. At the same time pathologists were taught the specific principles of handling and reporting of rectal cancer specimens. A national rectal cancer registry was established in conjunction with The Cancer Registry of Norway. Between November 1993 and December 1999, 5382 patients with rectal cancer were identified in Norway. At the end of this time period, more than $95 \%$ of the rectal cancer resections were TME procedures. Of the $3432(64 \%)$ patients who underwent a curative rectal resection, $8 \%$ had local recurrence. The 5 -year survival rate was $71 \%$ (among those $<75$ years). Implementation of an improved surgical technique (TME) has decreased the local recurrence rate from $28 \%$ to $8 \%$ and increased the 5-year survival rate from $55 \%$ to $71 \%$. 


\section{INTRODUKSJON}

Insidensen av rectumcancer i Norge har vist jevn økning gjennom de siste årtier, både for menn og kvinner. Fra 50-tallet til 90-tallet var insidensøkningen $150 \%$ (1). Sammenlignet med de andre nordiske landene er den norske økningen påfallende, da det ellers er en stabil eller fallende (Danmark) insidens i våre naboland (1). I samme periode har prognosen ved rectumcancer vært dårlig, selv etter antatt radikal behandling. Data fra våre universitetssykehus har vist at mellom $21 \%$ og $34 \%$ av pasientene fikk lokalt residiv i bekkenet (2,3). For perioden 1986-88 var det på landsbasis $28 \%$ av pasientene som utviklet lokalt residiv etter antatt kurativ behandling, og bare 55\% som overlevde fem år (4). Hos pasienter som utviklet lokalt residiv var 5-års overlevelsen 8\%. Disse nasjonale data var i overenstemmelse med utenlandske resultater (5).

De dårlige resultatene etter antatt radikal kirurgi for rectumcancer har selv i moderne litteratur $(6,7)$ vært vurdert som et faktum man ikke kunne komme bort fra. Utenlandske fagmiljøer, spesielt i USA, har derfor gått inn for adjuvant strålebehandling, evt. kombinert med kjemoterapi, noe som er standard rutine i de fleste land. Preoperativ stråling alene kan halvere frekvensen av lokale residiv, men uten sikkert å forlenge overlevelsen, og effekten av kjemoterapi ved rectumcancer er også usikker (8).

Det er kjent at resultatene etter kirurgi for rectumcancer har vist store variasjoner avhengig av hvilken kirurg som opererer (9-11). Dette ga grunnlag for idèen om at det måtte være mulig å skolere norske kirurger bedre for å heve behandlingsstandarden på landsbasis, selv uten adjuvant behandling. Hypotesen var at slike tiltak ville gi færre lokale residiv og bedre overlevelse.

I løpet av 80-tallet kom det rapporter fra enkeltavdelinger i England med kun 4-5\% lokalt residiv (12). Grunnlaget for de gode resultatene ble antatt å være en utvikling av den kirurgiske teknikken ved operasjon for rectumcancer. Spesielt ble det lagt vekt på den nitide disseksjonen i planet utenfor den mesorectale fascie. Derved fjernes hele rectum med mesorectum "in toto", dvs. hele spredningsveien for primærtumor, såkalt Total Mesorectal Exciton (TME) (13). Dette gir både større sjanse for disseksjon $\mathrm{i}$ god avstand til tumor og samtidig optimaliseres mulighetene for å få fjernet alle lymfeknutene i drenasjeområdet for rectum. Enkeltavdelinger i Norge hadde tatt i bruk tilsvarende operasjonsteknikk og kunne vise til like gode resultater (14) med bl.a. 4\% lokalt residiv.

Det var derfor grunn til å tro at en forbedret kirurgisk teknikk (TME) ville kunne bedre prognosen ved rectumcancer; dvs. at innføring av TME kunne medføre færre lokale residiv og dermed bedre overlevelsen. Etter hvert kom det også dokumentasjon på at kirurgi for rectumcancer burde utføres av færre og spesialiserte kirurger som var særlig utdannet i metoden og var interessert i fagområdet $(9-11,15)$. Slike tiltak ville kunne heve kvaliteten i behandlingen. Forutsetningen for å kunne si noe om at tiltakene virket var å overvåke behandlingen i et nasjonalt register for rectumcancer. Registeret kunne gi tilbakemeldinger til hver enkelt kirurgisk avdeling om deres egne resultater sammenlignet med det nasjonale gjennomsnitt. Dermed ville en ha et redskap for å kunne påvirke kvaliteten i behandlingen også på lokalt plan.

Målet med denne studien er å vise hvordan et initiativ fra et klinisk fagmiljø i løpet av få år klarer å bedre prognosen for en stor gruppe kreftpasienter på landsbasis. Via opplæring av kirurger, såvel teoretisk som praktisk, og en standardisering av rutiner for beskrivelse av patologiske preparater, har en lagt grunnlaget for utvikling innen fagområdet.

\section{METODE}

I 1994 ble Norsk Rectum Cancer Gruppe opprettet. Gruppen er sammensatt av to kirurger fra hver helseregion, en patolog, en onkolog samt en representant fra Kreftregisteret. Disse opprettet et spesialregister for rectumcancer. Den sentrale registerfunksjonen ble lagt til Kreftregisteret for å utnytte spesifikk fagkompetanse med hensyn til registrering av data for kreftpasienter. Ved hvert sykehus som opererer rectumcancer ble det oppnevnt en kontaktperson med ansvar for registrering og innsending av data.

Fra 1993 ble det i Norge arrangert en rekke kurs ved forskjellige sykehus for å lære kirurgene den nye operasjonsteknikken. Det ble også arrangert kurs for patologer for å heve standarden både av den makroskopiske og mikroskopiske vurderingen av operasjonspreparatene, basert på Quirkes metode (16). I tillegg er det lagt vekt på å standardisere histologibeskrivelsene. Dette har vært nødvendige tiltak for å sikre at resultatene kunne evalueres.

Rectumcancerregisteret innhenter data fra flere kilder. Alle kirurgiske avdelinger i Norge hvor det opereres rectumcancer melder demografiske og kliniske data på eget skjema. Via patologiavdelingenes obligatoriske meldinger til Kreftregisteret får man den histologiske vurderingen av operasjonspreparatene. Sammen med meldeskjema fra de kliniske avdelingene utgjør dette en garanti for at alle som får rectumcancer identifiseres. Opplysninger om forløpet av sykdommen innhentes via purrerutiner til de kirurgiske avdelinger, mens opplysninger om død overføres fra Statistisk Sentralbyrå. Ved siste oppdatering utført høsten 2000 har en innhentet opplysninger om de som ble diagnostisert i perioden fra november 1993 til og med desember 1999. Hver avdeling får regelmessig tilsendt sine egne resultater i tillegg til landsgjennomsnitt, slik at man kan sammenligne egne resultater $i$ forhold til landet for øvrig. Anonymiserte variasjonsanalyser gir muligheter for overvåkning av standarden over hele landet. Resultatene av landsgjennomsnitt og på helseregion nivå vil være offentlig tilgjengelige. 


\section{RESULTATER}

Rectumcancerregisteret inkluderer alle pasienter med endetarmskreft diagnostisert fra november 1993. Til og med desember 1999 dreide det seg om 5382 pasienter hvor svulsten ble lokalisert innen $16 \mathrm{~cm}$ fra anus. Det er operert rectumcancer ved 55 kirurgiske avdelinger i Norge i aktuelle periode, dvs. ved 7 universitetsklinikker, 14 sentralsykehus og 34 lokalsykehus.

Tabell 1 beskriver stadiefordelingen ved diagnosetidspunkt. Aldersfordelingen viser spredning fra 16 til 97 år, med median 69 år. Det var flere menn (56\%) enn kvinner (44\%). Ca. 30\% hadde så avansert sykdom at radikalbehandling av kreftsykdommen ikke var mulig, dvs. det var $9 \%$ som ikke ble operert og $21 \%$ som fikk utført en palliativ operasjon. Noen av disse hadde lokalavansert sykdom, mens andre hadde fjernmetastaser (Dukes'D). En del pasienter var for skrøpelige til å gjennomgå en stor reseksjon av rectum, og det var $6 \%$ som derfor fikk utført transanal, lokal eller endoskopisk reseksjon for sin cancer, oftest i tidlig stadium av sykdommen. Figur 1 viser fordeling av de forskjellige behandlingsmodalitetene.

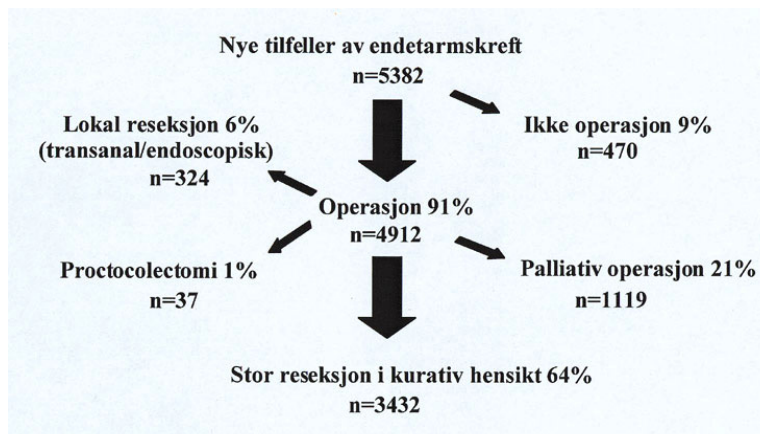

Figur 1. Oversikt over behandlingen for pasienter med endetarmskreft i perioden november 1993 til desember 1999.

Tabell 1. Data om 5382 pasienter med endetarmskreft i perioden november 1993 til desember 1999.

\begin{tabular}{lcr}
\hline & Antall & $\%$ \\
\hline Alder, median (variasjon) & $69(16-97)$ & \\
Menn & 3020 & 56 \\
Kvinner & 2362 & 44 \\
Ikke operert & 470 & 9 \\
Palliativ operasjon & 1119 & 21 \\
Lokal reseksjon & 122 & 2 \\
Endoskopisk reseksjon & 202 & 4 \\
Proktokolectomi & 37 & 1 \\
Kurativ reseksjon & 3432 & 64 \\
Dukes' A & 1355 & 25 \\
Dukes' B & 1390 & 26 \\
Dukes' C & 1217 & 23 \\
Dukes' D & 892 & 17 \\
Ukjent stadium & 528 & 10 \\
\hline
\end{tabular}

Det er i gruppen av pasienter som behandles med "stor reseksjon" i kurativ hensikt vi kan evaluere kvaliteten av den kirurgiske behandlingen. Disse utgjør $64 \%$ av pasientmaterialet.

Tabell 2 karakteriserer de 3432 pasientene (58\% menn og $42 \%$ kvinner) som ble operert i kurativ hensikt, med $65 \%$ lav fremre reseksjon, $29 \%$ rectumamputasjon og $6 \%$ Hartmanns prosedyre. I $38 \%$ av tilfellene hadde svulsten vokst gjennom tarmveggen (Dukes'B) og i 33\% av tilfellene var det spredning til lymfeknuter i mesorectum (Dukes'C). Aldersfordelingen er vist i figur 2. Selv om aldersvariasjonen er stor, er den vesentlige delen av pasientpopulasjonen mellom $45 \mathrm{og}$ 85 år. $11 \%$ (386) hadde tidligere hatt annen cancer. 30 dagers operasjonsmortalitet var 3\%. Strålebehandling ble gitt til $9 \%$ og kjemoterapi til $1 \%$ av de antatt radikalopererte. Implementeringen av TME i Norge er gjengitt $i$ figur 3 . Denne viser at det var en rask innføring av den nye metoden, da $78 \%$ ble operert med TME teknikken allerede i 1994 og hele 96\% i 1998.

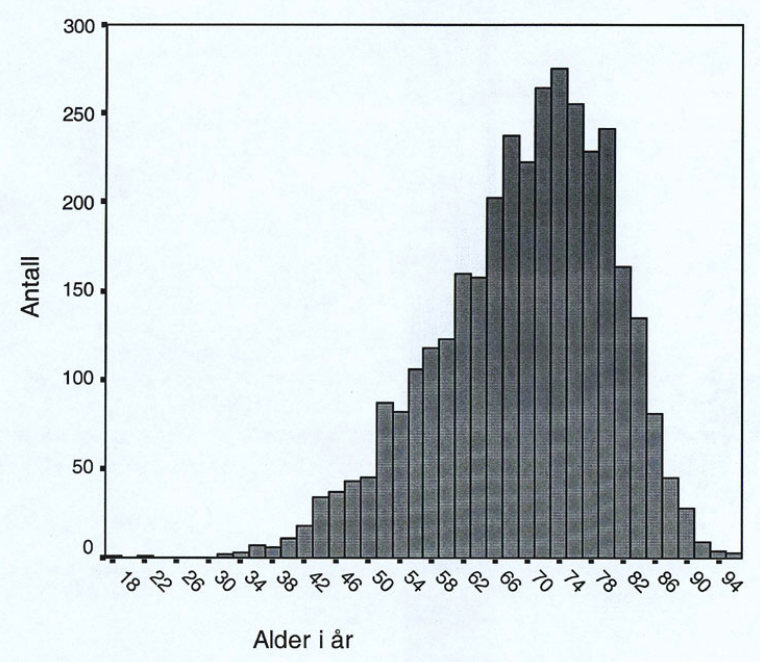

Figur 2. Aldersfordeling blant 3432 pasienter med endetarmskreft operert med kurativ intensjon.

Tabell 2. Data om 3432 pasienter med endetarmskreft operert med stor reseksjon i kurativ hensikt.

\begin{tabular}{lrr}
\hline & Antall & $\%$ \\
\hline Menn & 1985 & 58 \\
Kvinner & 1447 & 42 \\
Tidligere cancer & 386 & 11 \\
& & \\
Lav fremre reseksjon & 2235 & 65 \\
Rectumamputasjon & 985 & 29 \\
Hartmanns operasjon & 212 & 6 \\
Strålebehandlet & 308 & 9 \\
Ikke strålebehandlet & 3124 & 91 \\
& & \\
Dukes' A & 1008 & 29 \\
Dukes' B & 1288 & 38 \\
Dukes' C & 1136 & 33 \\
\hline
\end{tabular}




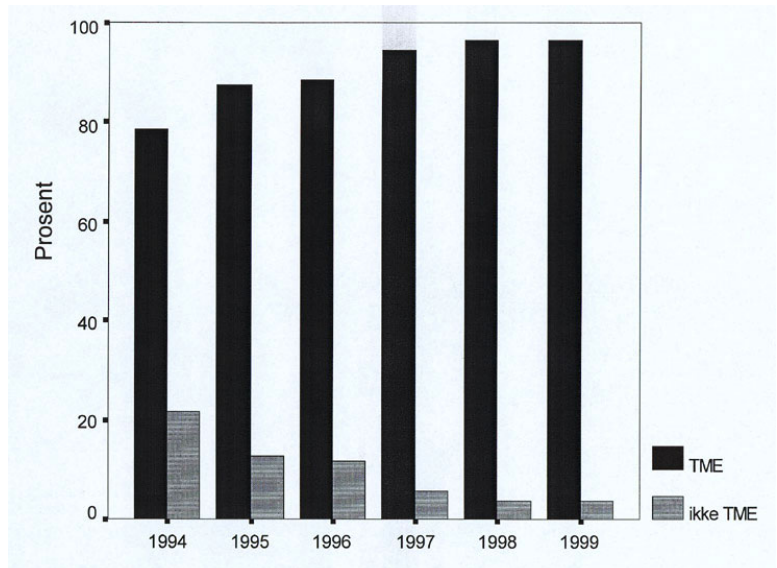

Figur 3. Prosentvis fordeling av operasjonsmetode for endetarmskreft, TME versus ikke TME.

Blant de antatt radikalopererte har $8 \%$ av pasientene utviklet lokalt residiv etter 31 måneder median observasjon, mens den estimerte raten etter fem år er $12 \%$. 5 -års overlevelse for pasienter under 75 år var $71 \%$.

\section{DISKUSJON}

Effektene av innføring av TME har vist seg å være betydelige. Fra å ha en lokal residiv rate på $28 \%$ i slutten av 1980-tallet, har prosjektet ført til en observert rate på $8 \%$ (estimert til $12 \%$ ved fem års observasjon). Samtidig har 5-års overlevelsen steget fra $55 \%$ til nå $71 \%$ for pasienter under 75 år. Resultatene er oppnådd gjennom tiltak som involverer mange aktører, bl.a. kirurger og patologer, samt overvåking av standarden gjennom et nasjonalt register.

TME metoden ble raskt innført på landsbasis, fra $78 \%$ i 1994 , til $96 \%$ fra 1998 . Et annet viktig poeng i denne prosessen har vært at fagmiljøet har lagt opp til at man skal være spesialist i gastroenterologisk kirurgi, eller under utdanning til denne spesialiteten og da veiledet av sertifisert spesialist, for å operere rectum- cancer. Dette står i kontrast til de nasjonale data for perioden 1986-88, da hver kirurg i gjennomsnitt bare opererte en til to pasienter for rectumcancer pr. år (4). Grunnen er at det tidligere var et spesifisert krav til utdannelsen i generell kirurgi om minst fem rectumoperasjoner, noe som medførte at lite erfarne kirurger opererte en del av disse pasientene. Det er nærliggende å tro at opplæring av spesialiserte kirurger har vært viktig for den positive utviklingen innen rectumcancerkirurgien, noe som også kan ha medvirket til at det nå er færre som får utlagt tarm, dvs. $35 \%$ nå mot $45 \%$ i perioden $1986-88$.

Det er bare ca. 9\% som har fått stråling, og da bare for de mest avanserte svulstene. Likevel er raten av lokale residiv på samme nivå som de fleste internasjonale studier hvor stråling er brukt $i$ utstrakt grad (17). Bedret kirurgi antas å redusere behovet for strålebehandling og kjemoterapi. Dermed spares pasientene for de toksiske effekter og komplikasjoner som adjuvant behandling gir og behandlingen blir enklere og bedre. Dessuten frigjøres det behandlingskapasitet for andre pasientgrupper som trenger strålebehandling eller kjemoterapi.

Rectumcancerregisteret har ikke bare gitt mulighet for overvåkning av standarden $\mathrm{i}$ behandlingen ved de forskjellige avdelinger, men de rutinemessige tilbakemeldingene til hver avdeling antas å inspirere hver enkelt kirurg og patolog til å yte sitt beste. Dette gir også mulighet til å korrigere egen praksis og er slik sett et viktig kvalitetsfremmende tiltak.

Som følge av et nasjonalt initiativ for å heve kvaliteten $i$ behandlingen av rectumcancer er prognosen etter radikaloperasjon blitt bedre for denne kreftformen. Det nasjonale samarbeidsprosjektet som knytter 55 kirurgiske avdelinger opp mot Kreftregisteret er et godt eksempel på hva god organisering kan gi av kvalitetsforbedring i kreftbehandlingen.

Støttet av Den Norske Kreftforening og Den Norske Laegeforenings Kvalitetssikringsfond II.

\section{APPENDIKS}

Styringsgruppe: Norsk Gastrointestinal Cancer Gruppe (NGICG) (Leder: Olav Dahl, Onkologisk avdeling, Haukeland Sykehus, Bergen).

Referansegruppen: Tormod Bjerkeset, Innherred Sykehus; Erik Carlsen, Ullevål Sykehus (Leder); Tor J. Eide, Rikshospitalet; Olav Dahl, Haukeland Sykehus; Tom Gerner, Oppland Sentralsykehus, Lillehammer; Frøydis Langmark, Kreftregisteret; Helge E. Myrvold, Regionssykehuset i Trondheim; Jarle Norstein, Kreftregisteret; Øivind Irtun, Regionssykehuset i Tromsø ; Geir Rønning, Nordland Sentralsykehus; Arne Skarstein, Haukeland Sykehus; Jon Arne Søreide, Sentralsykehuset i Rogaland; Johan N. Wiig, Radiumhospitalet.

\section{Deltagende sykehus og kontaktpersoner på disse:}

Aker Sykehus (Arild Nesbakken, M.D.), Sentralsykehuset i Akershus (Arne E. Færden, M.D.), Aust-Agder Sentalsykehus (Tore Gauperaa, M.D.), Buskerud Sentralsykehus (Ulf Jacobsen, M.D.), Bærum Sykehus (Rocio Rosales, M.D.), Diakonhjemmet Sykehus (Jan Helge Solhaug, M.D.), Diakonissehjemmets Sykehus (Trond Haugstvedt, M.D.), Gravdal Sykehus (Bjørn Bergsdal, M.D.), Hammerfest Sykehus (Svein Hammelbo, M.D.), Harstad Sykehus (Trond Ellingsen, M.D.), Fylkessykehuset i Haugesund (Knut Svendby, M.D.), Haukeland Sykehus (Arne Skarstein, M.D.), Sentralsykehuset i Hedmark (Øyvind Graadal, M.D.), Indre Østfold Sykehus (Thor Arnestad, M.D.), Inherred Sykehus (Tormod Bjerkeset, M.D.), Kirkenes 
Sykehus (Lennart Wählby, M.D.), Kongsberg Sykehus (Fredrik Kylberg, M.D.), Kongsvinger Sykehus (Mikael Bech, M.D.), Fylkessykehuset i Kristiansund (Håkan Steen, M.D.), Larvik Sykehus (Odd Ruistuen, M.D.), Oppland Sentralsykehus, Gjøvik (Olav Høstmælingen, M.D.), Oppland Sentralsykehus, Lillehammer (Bjørn H. Nilsen, M.D.), Fylkessjukehuset i Lærdal (Fritjof Lund-Larsen, M.D.), Fylkessjukehuset i Molde (Arve Sæbø, M.D.), Moss Sykehus (Torgeir Løvig, M.D.), Sentralsykehuset i Møre og Romsdal (Gustav R. Hareide, M.D.), Namdal Sykehus (Hallvard Græsli, M.D.), Narvik Sykehus (Tor Teigan, M.D.), Nordland Sentralsykehus (Jermund Liljedal jr, M.D.), Notodden Sykehus (Hans Thomas Fjære, M.D.), Fylkessjukehuset på Odda (Gauti Arnthorsson, M.D.), Orkdal Sanitetsforenings Sykehus (Kristen P. Benediktsson, M.D.), Rana Sykehus (Ranveig K. Aspevik, M.D.), Radiumhospitalet (Johan N. Wiig, M.D.), Rikshospitalet (Odd Søreide, M.D.), Ringerike Sykehus (John Colin Poole, M.D.), Rjukan Sykehus (Kjetil Unneberg, M.D.), Sentralsykehuset i Rogaland (Hartwig Kørner, M.D.), Sandefjord Sykehus (Hans Petter Næss, M.D.), Sandnessjøen Sykehus (John Kufås, M.D.), Sentralsykehuset i Sogn og Fjordane (Nils Sletteskog, M.D.), Stensby Sykehus (Johan Lykke, M.D.), Fylkessjukehuset på Stord (Olav Stray, M.D.), Storkmarknes Sykehus (Rune Svensen, M.D.), Telemark Sentralsykehus (John Bjørn Nilsen, M.D.), Regionssykehuset i Tromsø (Marit Hansen, M.D.), Regionssykehuset i Trondheim (Helge E. Myrvold, M.D.), Tynset Sykehus (Bjørn Nordby, M.D.), Ullevål Sykehus (Erik Carlsen, M.D.), Vefsn Sykehus (Øistein Ylvisaker, M.D.), Vest-Agder Sentralsykehus (Leif Ø. Heen, M.D.), Sentralsykehuset i Vestfold (Geir Haarberg, M.D.), Fylkessjukehuset i Volda (Yngve Nordervald, M.D), Fylkessjukehuset i Voss (Hans Jørgen Nielsen, M.D.), Østfold Sentralsykehus (Thorleif E. Wilhelmsen, M.D.).

\section{REFERANSER}

1. Langmark F. Cancer of the rectum: epidemiology, improvement in survival and the role of a national cancer registry. I: Søreide O, Norstein J, red. Rectal Cancer Surgery: Optimisation, Standardisation, Documentation. Berlin: Springer Verlag, 1997: 3-16.

2. Dahl O, Horn A, Morild I, et al. Low-dose preoperative radiation postpones recurrence in operable rectal cancer. Cancer 1990; 66: 2286-94.

3. Rein KA, Wiig JN, Sæther OD, Myrvold HE. Lokalt residiv ved cancer recti. Tidsskr Nor Lageforen 1987; 107: 2318-20.

4. Norstein J, Langmark F. Results of rectal cancer treatment: a national experience. I: Søreide O, Norstein J, red. Rectal Cancer Surgery: Optimisation, Standardisation, Documentation. Berlin: Springer Verlag, 1997: 17-28.

5. McCall JL, Wattchow DA. Failure after curative surgery alone. I: Søreide O, Norstein J, red. Rectal cancer surgery. Optimisation, Standardisation, Documentation. Berlin: Springer Verlag, 1997: 29-45.

6. Abulafi AM, Williams NS. Local recurrence of colorectal cancer: the problem, mechanisms, management and adjuvant therapy (Review). Br J Surg 1994; 81: 7-19.

7. Cohen AM, Winawer SJ, Friedman MA, Gunderson LL, red. Cancer of the Colon, Rectum and Anus. New York: McGraw-Hill, 1995.

8. Keighley MRB, Williams NS, red. Surgery of the Anus Rectum \& Colon, Vol. 1 (2nd Edn). London: W.B. Saunders, 1999: 1245-302.

9. McArdle CS, Hole D. Impact of variability among surgeons on postoperative morbidity and mortality and ultimate survival. BMJ 1991; 302: 1501-5.

10. Holm T, Johansson H, Cedermark B, et al. Influence of hospital- and surgeon-related factors on outcome after treatment of rectal cancer with or without preoperative radiotherapy. Br J Surg 1997; 84: 657-63.

11. Hohenberger W. The effect of specialization or organization of rectal cancer surgery. I: Søreide O, Norstein J, red. Rectal Cancer Surgery: Optimisation, Standardisation, Documentation. Berlin: Springer Verlag, 1997: 353-63.

12. Heald RJ, Ryall RD. Recurrence and survival after total mesorectal excision for rectal cancer. Lancet 1986; i: 1479-82.

13. Heald RJ, Husband EM, Ryall RD. The mesorectum in rectal cancer surgery - the clue to pelvic recurrence? Br J Surg 1982; 69: 613-6.

14. Bjerkeset T, Edna T-H. Rectal cancer: the influence of type of operation on local recurrence and survival. Eur J Surg 1996; 162: 643-8.

15. Hermanek P, Wiebelt H, Staimer D, Riedl S and the German Study Group Colo-Rectal Carcinoma (SGCRC). Prognostic factors of rectum carcinoma: experience from the German Multicentre Study SGCRC. Tumori 1995; 81 (suppl.): 60-4.

16. Quirke P, Dixon MF. How I do it: The prediction of local recurrence in rectal adenocarcinoma by histopathological examination. Int J Colorectal Dis 1988; 3: 127-31.

17. Randomized study on preoperative radiotherapy in rectal carcinoma. Stockholm Colorectal Cancer Study Group. Ann Surg Onc 1996; 3: 423-30. 
